\title{
A Formação Continuada como fator responsável pela eficácia do uso das NTICS na Escola Érico Veríssimo Município De Simões-Pi
}

\author{
Nerivaldo Brás de Carvalho ${ }^{1}$; Raimunda Tânia Pinheiro de Oliveira ${ }^{2}$
}

\begin{abstract}
Resumo: O objeto de análise deste trabalho foi à formação continuada dos professores para o uso das tecnologias atuais na Escola Érico Veríssimo município de Simões - PI e tem como objetivo analisar a utilização desses novos instrumentos tecnológicos, verificar quais as metodologias e atividades com tecnologias desenvolvidas pelos professores da escola. Avaliar as principais dificuldades enfrentadas pelos professores na utilização das tecnologias de informação no contexto escolar e se estão sendo utilizada na escola como ferramenta facilitadora no processo ensino-aprendizagem, bem como, identificar os benefícios do uso das TICs no processo ensino e discutir as mudanças ocorridas na prática dos docentes com a inserção das tecnologias atuais no ambiente escolar. Esse trabalho se constitui em uma pesquisa de campo e bibliográfica. Como ponto de partida, o estudo foi fundamentado nas ideias de diferentes autores que versam a respeito do tema. Dentre esses estudiosos, temos Valente (1993), Almeida (1998), Masetto (2000) e Kenski (2009). Durante a pesquisa pode-se verificar a importância da formação continuada dos profissionais da educação para utilizar de forma consciente as Tecnologias atuais e a eficácia desse processo para o ensino, haja visto que com a inserção da mesma o aluno passa a desenvolver melhor seu aprendizado e conhecimento, de forma clara e objetiva.
\end{abstract}

Palavras-Chave: Educação, Informática, Formação Continuada; Tecnologias;

\section{The Continuing Education as a factor responsible for the effectiveness of the use of NTICS at Érico Veríssimo School in Simões Municipality, PI}

\begin{abstract}
The objective of this work was the continuous training of teachers for the use of current technologies at Érico Veríssimo School in Simões Municipality,PI and aims to analyze the use of these new technological instruments, verify which methodologies and activities with developed technologies By the school teachers. Evaluate the main difficulties faced by teachers in the use of information technologies in the school context and are being used in school as a facilitating tool in the teaching-learning process, as well as to identify the benefits of using ICTs in the teaching process and discuss the changes that have occurred In the practice of teachers with the insertion of current technologies in the school environment. This work constitutes a field and bibliographical research. As a starting point, the study was based on the ideas of different authors who talk about the theme. Among these scholars, we have Valente (1993), Almeida (1998), Masetto (2000) and Kenski (2009). During the research it is possible to verify the importance of the continuous training of the professionals of the education to use conscientiously the current Technologies and the effectiveness of this process for the teaching, since with the insertion of the same one the student begins to develop better its learning and Knowledge, in a clear and objective way.
\end{abstract}

Keywords: Education, Information Technology, Continuing Education; Technologies;

\footnotetext{
${ }^{1}$ Graduado em Matemática e Normal Superior - UESPI. Especialista em Psicopedagogia - SOET. Mestrando em Educação pela Anne Sullivan University. Professor Efetivo da Rede Municipal de Ensino Simões - PI. E-mail:nerybraz@ hotmail.com;

2 Bióloga- Mestra pela Universidade Federal do Ceará (2001)- vivência no ensino da Biologia Geral, com ênfase em Microbiologia, Administração Educacional e Métodos e Técnicas de Ensino (t.biologa@gmail.com).
} 
Id on Line Revista Multidisciplinar e de Psicologia

Id on Line Multidisciplinary and Psycology Journal

\section{Introdução}

As Tecnologias de Informação e Comunicação - TICs contribuem, de forma significativa, na educação, facilitando o processo ensino-aprendizagem. Sendo assim, a eficácia do uso dessas novas ferramentas pedagógicas, depende principalmente da forma como estão sendo utilizadas no contexto da sala de aula.

Nesse sentido, o professor assume maior responsabilidade em relação à transformação e êxito de sua prática pedagógica. Ao incorporar as Tecnologias de Informação e Comunicação aos seus métodos e estratégias, esse profissional contribui com a melhoria da qualidade da educação, desde que esteja preparado e qualificado para o uso consciente e adequado dessas tecnologias educacionais.

O uso das tecnologias atuais na sala de aula, muitas vezes é limitado por medo do novo, ou simplesmente por ver essas ferramentas atuais como algo difícil para trabalhar, porque os alunos têm mais domínios que muitos professores. Porém, o que se sabe é que as tecnologias não vieram para dificultar a vida das pessoas, mas sim para ajudar e facilitar muitas atividades que seriam difíceis de serem realizadas sem a presença desses recursos.

É importante o uso das tecnologias atuais, para acompanhar a evolução do processo de ensino dentro e fora das salas de aula. Com isso, vemos um avanço nos métodos e técnicas para a melhoria, na eficácia do ensino-aprendizagem.

Ainda existe uma grande preocupação quanto à preparação dos profissionais de educação para a utilização correta desses recursos, em especial, dos professores, dentro e fora da sala de aula, aplicando de forma correta as novas ferramentas que estão surgindo.

Diante disso, é importante uma reflexão sobre essa nova perspectiva, repensar o uso de novas práticas pedagógicas com a utilização de recursos tecnológicos. Em presença desse fator surge à problemática: se existem ferramentas disponíveis na escola porque não utilizá-la como meio de renovar as práticas educativas pedagógicas?

A escolha desse tema justifica-se pela necessidade de incorporar as TICs à prática docente, enfatizando a importância da formação continuada desses profissionais, uma vez que a tecnologia está presente em todos os setores sociais, inclusive na área educacional e como não é possível ignorá-la, faz-se necessário inseri-la nesse contexto. 
Id on Line Revista Multidisciplinar e de Psicologia

Id on Line Multidisciplinary and Psycology Journal

É preciso entender como está sendo o uso desses novos recursos tecnológicos na escola e verificar como os educadores estão se adaptando a esse novo modelo de transmitir conhecimento, pois conhecer novos métodos de ensino utilizando as tecnologias atuais é de grande importância para a atualização e formação integral do individuo.

\section{Os Avanços das Tecnologias e a Importância da Formação Continuada Para o Bom Uso da Mesma.}

As tecnologias atuais tem se apresentado como ferramenta relevante nas diversas ações da sociedade moderna. Pois diminuem empecilhos que impedem o progresso do indivíduo. Como mediador deste processo na educação, o professor deverá lançar desafios e experiências que envolvam seus alunos e que os levem a vencer suas dificuldades, principalmente no âmbito da aprendizagem. Sendo assim, poderá desenvolver uma metodologia que virá atender anseios de seu público de trabalho. Para tanto, poderá encontrar diversas formas de se apropriar de recursos digitais como ferramentas de ensino e aprendizagem.

Os avanços das tecnologias nos dias de hoje são crescentes e com elas, vem surgindo o progresso nas formas de passar o conhecimento nas salas de aula. $\mathrm{O}$ presente artigo fala das tecnologias atuais, os múltiplos recursos da mesma que podem ser trabalhados na educação e da formação continuada para que os professores possam trabalhar essas ferramentas adequadamente.

Em conjunto, é dever dos professores e demais profissionais envolvidos com o ensino em geral, manter uma atualização e capacitação para uso dos novos mecanismos apresentados e que ajudam a dinamizar e dar mais eficiência ao aprendizado de seu público-alvo.

Com a chegada do rápido crescimento e aparecimento dessas tecnologias todas as formas de ensino não puderam ficar de fora e não poderiam devido o aumento de informações, onde na maioria das vezes os alunos tem mais contato com a informática em casa do que na escola. Como podemos observar:

Com a tecnologia cada dia mais presente nos dias de hoje, nas escolas, o perfil do professor está mudando, mas ainda temos muitos que estão completamente fora dessa realidade vivenciada por muitos alunos. Muitos alunos têm contato com a tecnologia desde pequenos, principalmente com o uso do computador. (BORBA, MDC; PENTEADO, 2001). 
Porém, o que podemos observar na maioria das vezes, é uma falta de capacitação dos profissionais envolvidos com a educação, levando a ser criada uma barreira entre os profissionais e os recursos que lhes são apresentados. Assim, vemos:

\begin{abstract}
As experiências de implantação da informática na escola têm mostrado que a formação de professores é fundamental e exige uma abordagem totalmente diferente. Primeiro, a implantação da informática na escola envolve muito mais do que prover o professor com conhecimento sobre computadores ou metodologias de como usar o computador na sua respectiva disciplina. Existem outras barreiras que nem o professor nem a administração da escola conseguem vencer sem o auxílio de especialistas na área. Por exemplo, dificuldades de ordem administrativa sobre como viabilizar a presença dos professores nas diferentes atividades do curso ou problemas de ordem pedagógica: escolher um assunto do currículo para ser desenvolvido com ou sem o auxílio do computador. Segundo, os assuntos desenvolvidos durante o curso devem ser escolhidos pelos professores de acordo com o currículo e a abordagem pedagógica adotadas pela sua escola. (VALENTE; DE ALMEIDA, p-45, 1997).
\end{abstract}

Percebe-se que o problema da informática nas escolas, vai além de apenas usar ou fomentar seu uso. É de caráter organizacional geral, onde os profissionais devem trabalhar de forma conjunta para chegarem ao seu fim, com êxito e eficiência.

A observação foi feita na escola municipal Érico Veríssimo - Simões PI. Os sujeitos pesquisados foram alguns professores da referida escola. A mesma funciona em dois turnos, manhã e tarde, do infantil ao fundamental II, composta por 638 alunos e 48 funcionários. Para a coleta de dados foi feito visitas à escola e observação. Além de aplicação de questionários com perguntas abertas e fechadas para doze professores.

Diante da análise das respostas dos Professores, verificou-se que o uso dos recursos tecnológicos na sala aula pode trazer melhoria para a qualidade do ensino, visto que essas ferramentas ajudam a fugir das aulas tradicionais, sempre chamando mais a atenção do aluno, e isso faz com que as aulas se tornam mais atrativas.

A partir das informações coletadas através dos questionários com os sujeitos da pesquisa, obtiveram-se os seguintes resultados.

Ao questionar sobre o que esses profissionais entendem por tecnologia de informação e comunicação, verificou-se que, dos doze professores, oito souberam responder com clareza. Segundo os professores "entende-se por tecnologia de informação e comunicação, as tecnologias desenvolvidas com o intuito de comunicação e disseminação do conhecimento por meio de formas interativas, colaborativas e integradoras". 
Id on Line Revista Multidisciplinar e de Psicologia

Id on Line Multidisciplinary and Psycology Journal

Através de uma análise na escola Érico Veríssimo, na cidade de Simões - PI, buscou saber quais instrumentos de informática e das tecnologias atuais foram introduzidos para melhorar o rendimento no ensino, saber se os profissionais estão ou não preparados para trabalharem com as novas ferramentas apresentadas".

De acordo com Masetto (2000), podemos considerar as TICs como recursos de linguagens digitais de que atualmente dispomos e que podem colaborar significativamente para tornar o processo de educação mais eficiente e mais eficaz. Dessa forma, as tecnologias aliadas à educação buscam facilitar o processo de ensino-aprendizagem através de uso de diferentes metodologias e, uma vez que a cada dia surgem novos recursos. Com isso, a escola deve buscar adaptar o seu sistema de ensino à realidade da sociedade contemporânea, melhorando assim a qualidade da educação.

\section{Os Recursos Tecnológicos da Escola e a Opinião dos Professores Quanto ao Uso das Tic's.}

A escola deve ser a principal incentivadora no processo de transformação educacional. De acordo com os professores participantes dessa pesquisa, a referida escola possui alguns recursos tecnológicos que facilitam o processo de ensino-aprendizagem, tais como: “computadores, câmeras de vídeos, Datashow, televisão, impressora, aparelho de DVD, lousa digital, Microsystems, microfone, tela de projeção e caixa de som, sendo que nem todas são utilizadas". Três, dos professores, acrescentaram que o uso do laboratório de informática por partes dos alunos é inacessível, pois se encontra fechado, o que acaba prejudicando o uso da informática como recurso de ensino.

Em relação aos benefícios que as TICs promovem no processo educacional, os professores foram unânimes, em dizer que: utilizar as tecnologias aliadas à educação melhora a qualidade do ensino; torna as aulas atrativas, inovadoras; diminui o índice de reprovação; melhora o desempenho do aluno, despertando o interesse, a curiosidade, além de aumentar a interação e favorecimento do diálogo entre professores e alunos.

O perfil dos nossos alunos mudou e as práticas docentes precisam acompanhar essas transformações, por isso a educação enfrenta um grande desafio, que é construir um espaço de mediação entre o aluno e o mundo tecnológico. 
Id on Line Revista Multidisciplinar e de Psicologia

Id on Line Multidisciplinary and Psycology Journal

Quanto à formação profissional na área da informática, nenhum dos professores pesquisados possui formação específica para a utilização das TICs no ambiente escolar. Conforme Kenski (2009), um dos grandes desafios que os professores brasileiros enfrentam está na necessidade de saber lidar pedagogicamente com alunos e situações extremas. O professor precisa estar preparado para as diferentes realidades, saber lidar com nativos e migrantes digitais, com recursos tecnológicos avançados ou até mesmo a ausência de recursos, ou seja, a dificuldade maior, ainda se encontra no que se refere à capacitação profissional.

Sabe-se que é bem mais difícil para os professores experientes que são imigrantes digitais dominarem os recursos tecnológicos da atualidade do que para os alunos da atualidade que são nativos digitais, mas para que a educação dê um passo significativo, é necessário que os professores se preparem e façam uso das tecnologias atuais, pois essas mudanças exigem esforço, paciência e persistência, e muitos infelizmente, não estão dispostos a mudar, talvez pelo desgaste da profissão ou por se considerarem sobrecarregados.

Apesar de não possuírem formação na área da informática da educação, os professores pesquisados afirmaram fazer uso das TICs em algum momento de sua prática pedagógica docente, quando dizem que "utilizam esses novos recursos como um importante aliado no planejamento e execução das aulas, pois podemos fazer pesquisas, utilizar as diferentes mídias, baixar vídeos, filmes direto da internet, para auxiliar na aprendizagem dos nossos alunos, a fim de tornar as aulas mais atrativas e prazerosa e uma aprendizagem mais significativa".

Segundo Almeida (2001, p. 43), o professor, ao incorporar as TICs aos seus métodos e estratégias, além de desenvolver a habilidade de uso das mesmas, estabelece uma ligação entre esse domínio, a prática docente, as teorias educacionais, refletindo sobre sua própria prática buscando transformá-la.

É importante ressaltar que todos os professores fazem uso de algum tipo de tecnologias na escola, afinal, a própria fala humana, a escrita, livros, revistas são tecnologias. O que as difere das atuais é o fato de não serem informatizadas. Por essa razão, as TICs necessitam de um conhecimento específico para utilizá-las de forma adequada, a favor da educação.

Segundo quatro professores que fazem uso frequente desses recursos, as metodologias de ensino foram modificadas com a chegada das TICs no ambiente escolar.

Percebe-se que houve mudanças significativas principalmente em relação ao interesse do aluno, que se torna mais curioso e disposto a aprender. Três professores afirmaram que as 
Id on Line Revista Multidisciplinar e de Psicologia

Id on Line Multidisciplinary and Psycology Journal

aulas se tornam mais atraentes deixando de ser monótonas, havendo uma maior interação e diálogo. Outros três professores afirmam que não fazem uso frequente, mas sempre que necessário recorrem a esses recursos tecnológicos.

Veiga (1991), afirma que professor precisa ter consciência de que o seu papel não é somente transmissão, mas sim de incentivar nos alunos a participação e a criticidade. A utilização de diferentes mídias torna as aulas bem mais atrativas, pois atualmente até mesmos as redes sociais podem ser usadas como ferramentas de ensino, devido ao seu uso por grande parcela da população mundial.

Com isso, o uso dessas ferramentas tecnológicas com o auxílio da internet, oferece várias oportunidades de aprendizagens, seja por meio de pesquisas, produções ou como forma de disseminação do conhecimento, por meio de blogs, jogos e softwares educativos. Haja visto que a interação e preparação dos profissionais de educação com as novas tecnologias apresentadas, são de fundamental importância para que dê certo todo o funcionamento esperado.

Foi aplicado questionários aos professores com intuito de saber o que eles acham da inclusão da informática na escola; como era feita a inclusão de novas tecnologias no âmbito escolar; se há capacitação dos profissionais para o uso dos instrumentos de informática disponíveis na escola; com que frequência usam tais recursos; sobre a disponibilidade dos materiais; e como se sentiam, em termos técnicos para relacionar o ensino usando as tecnologias atuais.

Colhidos os resultados foi constatado que $100 \%$ dos professores participantes da pesquisa, tem a mesma visão sobre a questão e a tratam da mesma forma.

Os professores participantes da pesquisa mostraram, de forma unânime, que: na atualização pessoal e profissional para servir como capacitação; há a falta de treinamento e capacitação por parte dos órgãos públicos relacionados á escola, gerando uma intimidação na utilização de tais recursos; alguns desses instrumentos nunca foram utilizados, pois apenas chegaram à escola e nunca houve quem os instruísse para a devida utilização. Eles são conscientes do benefício da informática na melhoria da educação, e são cientes da falta que a utilização desses recursos está fazendo nas salas de aula. 
Id on Line Revista Multidisciplinar e de Psicologia

Id on Line Multidisciplinary and Psycology Journal

Importante frisar que todos os professores entrevistados começaram a trabalhar na escola no mesmo período e tem a mesma percepção de capacitação ao longo desse tempo. O que nos ajudou a impedir uma disparidade nas informações coletadas.

Deixando os questionários por uma semana com os professores escolhidos, os mesmos ficaram a vontade para responder e mostrar a real situação de como podem trabalhar com a informática na sala de aula da escola que serviu como campo de pesquisa.

Pela observação feita na própria escola, pode-se perceber que ainda é pouco a utilização das tecnologias atuais, sendo que é uma pequena parcela dos professores que utilizam tais ferramentas e estes usam com pouca frequência, talvez pela falta de motivação e preparação para uso constante em sala de aula, mesmo sabendo que esses novos recursos podem dinamizar e melhorar a forma de ensino, gerando consequentemente, uma melhor aprendizagem.

$\mathrm{Na}$ escola Érico Veríssimo, pode-se perceber que alguns professores até se esforçam para acompanhar as novas técnicas e instrumentos para a introdução das tecnologias atuais em salas de aula. Porém, não há por parte das esferas responsáveis, uma capacitação adequada para que os mesmos possam fazer o uso correto e eficaz desses recursos.

A escola supracitada, tem dez computadores completos para o funcionamento da inclusão digital no espaço escolar. Os professores e gestores da escola, todos são especializados, porem nenhum possui formação ou capacitação para instrumentalizar esses recursos tecnológicos atuais.

Os doze professores entrevistados demostram experiência, tanto no que se refere à idade cronológica quanto na formação. Estas situações tornam-se favoráveis sobre o assunto e suas experiências e vivencias fazem perceber o quanto é importante aprender novas metodologias com os recursos tecnológicos.

Um dos questionamentos usado na pesquisa foi a respeito da concepção dos professores sobre o uso da informática na educação. Observa-se que nas respostas deles todos têm uma ideia, um conhecimento do que seja tecnologia de informação, reconhecem que os recursos tecnológicos é uma ferramenta indispensável para que se possa inovar em suas metodologias, e proporcionar uma verdadeira evolução no processo ensino-aprendizagem.

De acordo com Valente (1993), utilizar o computador como uma ferramenta educacional que auxilia no desenvolvimento da construção da aprendizagem é enriquecer e favorecer no processo pedagógico. 
Id on Line Revista Multidisciplinar e de Psicologia

Id on Line Multidisciplinary and Psycology Journal

Uma das questões foi referenciada a posição dos professores quanto às dificuldades encontradas com a utilização da informática dentro do contexto escolar. Através do resultado obtido observa-se que um dos professores entende que falta de conhecimento quanto ao manuseio desses equipamentos sofisticados é uma das dificuldades enfrentadas por ele. Dois deles enfatizam que a dificuldade está por falta de recursos nas escolas e formação continuada para saber lidar com o novo. Ainda teve um dos professores que disse: "São muitos os obstáculos encontrados ao utilizar os recursos tecnológicos atuais, tenho dificuldades até em realizar atividades simples, como baixar vídeos, montar slides etc.".

Nas reflexões de Cox (2008), o mesmo afirma que seja dada aos diretores e professores a oportunidade de conhecer as formas de uso da informática a serviço da educação, para que se possa adequá-la a novas metodologias.

$\mathrm{Na}$ terceira questão, tem referência ao ponto de como os professores utiliza em sua pratica, metodologias que auxilia na aprendizagem dos educandos com os recursos das tecnologias atuais. Percebe-se que dos entrevistados, poucos utilizam os recursos tecnológicos da atualidade em suas metodologias, e os que usam, emprega em fazer pesquisa, digitar atividades e avaliações.

De acordo com Nascimento 2007, com os recursos da informática é possível a realização de diversas ações como: fazer pesquisa, redigir textos, criar desenhos, fazer cálculos e desenvolver diversas habilidades.

Uma das questões estava voltada para a formação continuada dos professores para que os mesmos possam utilizar as tecnologias atuais. Foi relatado nas repostas deles que na escola que eles trabalham não é ofertado nenhum tipo de formação continuada que ofereça aos educadores condições básica para que os mesmos possam utilizar na sua prática educativa.

Segundo Almeida (1998), para que o professor tenha condições de criar ambientes de aprendizagem é preciso que o mesmo esteja preparado para desenvolver competências e habilidades, e que o mesmo esteja aberto a aprender e a dominar recursos computacionais dentro do contexto educacional.

Diante das dificuldades encontradas pelos professores na utilização das tecnologias de informação no contexto escolar, constatou-se que os professores não utilizam em sua prática metodológica por falta de capacitação, por essa razão faz-se necessário que seja realizado um trabalho voltado para a formação continuada dos educadores para que os mesmos possam ter 
Id on Line Revista Multidisciplinar e de Psicologia

Id on Line Multidisciplinary and Psycology Journal

conhecimentos sobre os recursos tecnológicos e se torne capaz de desenvolver práticas educativas renovadas.

\section{Metodologia}

Com a finalidade de analisar o uso das TICs na escola, utilizou-se, como instrumento de coleta de dados, questionários abertos, aplicados na escola escolhida, cujos sujeitos pesquisados foram doze professores do Ensino Fundamental II, do turno da tarde da Escola Municipal Érico Veríssimo do município de Simões-PI, com o intuito de investigar se esses profissionais da educação estão preparados para utilizar as novas Tecnologias de Informação e Comunicação em sua prática docente. As informações obtidas foram utilizadas como relatos fundamentais para a elaboração e construção do presente trabalho.

Com as colocações feitas por os educadores da escola darão uma dimensão de como é o trabalho dos professores com as tecnologias atuais. Segundo alguns entrevistados, o uso das TIC's é necessário no ambiente escolar, uma vez que enriquece as atividades propostas e desenvolve o interesse e interatividade dos alunos.

É possível comparar os resultados obtidos na observação, a fim de analisar a importância da formação continuada para que os professores possam inserir as Tecnologias da informação e comunicação em seus planejamentos.

Para observar a função e o desempenho de cada professor quanto ao uso de instrumentos tecnológicos existentes na escola, foi feita perguntas pertinentes ao tema da pesquisa, reunindo as informações necessárias para saber se os recursos tecnológicos recebidos pela Escola Érico Veríssimo foram recepcionados da forma correta e se houve uma preparação dos profissionais que atuam na escola, para que os mesmo possam fazer uma boa utilização desses novos recursos no âmbito escolar.

Essa pesquisa foi satisfatória, uma vez que as tecnologias atuais é algo de interesse do alunado, e quaisquer mecanismos que as envolvam, será tida pelo corpo discente como interessante e envolvente, tornando as aulas mais atrativas e deixando-os mais empenhados com o ensino, em busca de uma aprendizagem significativa. 
Id on Line Revista Multidisciplinar e de Psicologia

Id on Line Multidisciplinary and Psycology Journal

\section{Considerações Finais}

Com base no levantamento realizado, através dos resultados obtidos, notou-se que os professores sente muita dificuldade em utilizar os recursos tecnológicos nas suas aulas e essa dificuldade é por falta de conhecimento de como utilizar os recursos em suas metodologias. Por essa razão é indispensável à capacitação dos educadores para que os mesmos possam ter condições de inovar suas práticas metodológicas de forma eficiente e renovada.

Verificou-se que os educadores reconhecem que as tecnologias atuais é um forte recurso capaz de potencializar o desenvolvimento cognitivo dos alunos, e que sente a necessidade de uma formação continuada para que possam melhorar suas metodologias e práticas, para que possam aprofundar seus conhecimentos com essas novas ferramentas.

Pode-se concluir através dos questionários aplicados aos professores da escola em estudo, que todos tem um conhecimento sobre a importância do uso das tecnologias na educação, mas que sente dificuldade em utilizar em suas metodologias. Por essa razão, faz-se necessário que seja feito um trabalho voltado para a formação continuada dos educadores para que a tecnologia seja utilizada de forma necessária e correta.

Nota-se que os professores são empenhados e tendem para a atualização e evolução quanto à utilização das tecnologias atuais na escola. Porém, a falta de incentivo e capacitações faz com que eles deixem de lado instrumentos que poderiam melhorar de forma significativa o ensino e gerar benefícios positivos para toda a escola.

Considera-se o uso das TICs no ambiente escolar uma ferramenta pedagógica fundamental no processo de ensino-aprendizagem, pois proporciona vários benefícios para a educação, quando utilizadas de forma adequada. Por isso, a capacitação profissional é indispensável em qualquer área, principalmente no magistério.

As tecnologias invadiram os diversos setores sociais e avançam a cada dia, com isso a educação tende a se transformar, buscando incorporar novos elementos com o intuito de acompanhar a era da informatização. Assim sendo, as escolas devem adaptar o currículo a essa realidade. 
O professor adquire papel relevante nas transformações dos métodos de ensino, cabendo a esses profissionais despertar o interesse dos alunos, mediando à construção do conhecimento, por meio do uso desses novos recursos.

Portanto, o uso das tecnologias atuais na sala de aula, representa um novo paradigma educacional e os professores por sua vez, devem buscar uma formação profissional à medida que a sociedade se modifica.

Os educadores demonstraram saber da importância das TIC's no processo educacional e da responsabilidade em desenvolver atividades inovadoras usando as tecnologias, adequando esses recursos em sua metodologia para melhor construção do conhecimento dos alunos. E a escola objeto de pesquisa tem vários recursos tecnológicos em seu poder, os quais podem contribuir no processo ensino-aprendizagem, mas ainda são poucos para atender a grande demanda.

Conclui-se que, não só na realidade da escola estudada, mas de todo o ensino em geral, há dificuldade na preparação dos professores para acompanharem as tecnologias que chegam às escolas. Assim, eles não conseguem introduzir tais recursos nas salas de aula, deixando de lado um grande trunfo para melhoria do ensino. Com isso, professores e alunos são prejudicados por essa realidade. Perdem a oportunidade de aprender mais e de forma dinâmica.

\section{Referências}

ALMEIDA, M. E.B. Educação, projetos, tecnologia e conhecimento. São Paulo: PROEM, 2001. 63p.

. Novas tecnologias e formação de professores reflexivos. In: Anais do IX ENDIPE (Encontro Nacional de Didática e Prática de Ensino), Águas de Lindóia, p.1-6, 1998.

BORBA, MDC; PENTEADO, Miriam Godoy. Informática na Educação. Belo Horizonte: Autêntica, 2001;

COX, KENIA KODEL. Informática na Educação Escolar. São Paulo: Campinas, 2008.

KENSKI, V. M. Educação e tecnologias: o novo ritmo da informação. 5ed. Campinas, SP: Papirus, 2009. 141p. 
MASETTO, Marcos T. Mediação pedagógica e o uso da tecnologia. In: MORAN, José Manuel; MASETTO, Marcos T.; BEHRENS, Marilda Aparecida. Novas tecnologias e mediação pedagógica. 12 ed. Campinas: Papirus, 2000. 173p.

NASCIMENTO, JOÃO KERGINALDO FIRMINO DO. Informática aplicada à educação. Universidade de Brasília, 2007.

VALENTE, José Armando; DE ALMEIDA, Fernando José. Visão analítica da informática na educação no Brasil: a questão da formação do professor. Revista Brasileira de Informática na Educação, v. 1, n. 1, p. 45, 1997.

UNICAMP. 1993.

Computadores e conhecimento: repensando a educação. Campinas:

VEIGA, I. P. A.; CARDOSO, M. H. F. (Orgs). Escola fundamental: currículo e ensino. Campinas, SP: Papirus, 1991.

Como citar este artigo (Formato ABNT):

CARVALHO, N.B.; OLIVEIRA, R.T.P. A Formação Continuada como fator responsável pela eficácia do uso das Ntics na Escola Érico Veríssimo Município de Simões-PI. Id on Line Revista Multidisciplinar e de Psicologia, Nov-Dez. de 2016, vol.10, n.32, p. 28-40. ISSN: 1981-1179.

Recebido: 10/11/2016

Aceito: $14 / 11 / 2016$ 